\title{
Changes of Corneal Optical Properties after UVB Irradiation Investigated Spectrophotometrically
}

\section{Č. ČEJKA ${ }^{1,4}$, J. PLÁTENÍK ${ }^{2}$, J. ŠIRC ${ }^{3}$, T. ARDAN ${ }^{1}$, J. MICHÁLEK ${ }^{3}$, B. BRŮNOVÁ ${ }^{4}$, J. ČEJKOVÁ ${ }^{1}$}

${ }^{1}$ Laboratory of Eye Histochemistry and Pharmacology, Institute of Experimental Medicine, Academy of Sciences of the Czech Republic, Prague, Czech Republic, Institute of Medical Biochemistry, First Faculty of Medicine, Charles University, Prague, Czech Republic, ${ }^{3}$ Institute of Macromolecular Chemistry, Academy of Sciences of the Czech Republic, Prague, Czech Republic, ${ }^{4}$ Eye Clinic for Children and Adults, Second Faculty of Medicine, Charles University, Prague, Czech Republic

Received July 24, 2009

Accepted September 9, 2009

On-line November 20, 2009

\section{Summary}

Ozone depletion leads to an increase in UV rays of solar radiation reaching the surface of the Earth which is harmful to biological systems. Of the eye, the cornea is directly open to increased amount of UV rays of which mainly UVB rays are capable to induce reactive oxygen species damaging the cells. Previous studies showed that the irradiation of the cornea with UVB rays leads to morphological as well as metabolic disturbances of the cornea. Also, corneal hydration and corneal light absorption are increased after UVB rays. These changes were observed after five days of repeated irradiation of the cornea with UVB rays. The aim of the present paper was to examine how early the changes of corneal hydration and light absorption occur after UVB irradiation. The rabbit corneas were irradiated with UVB rays for one, two, three or four days. Corneal light absorption was examined spectrophotometrically and corneal hydration measured by pachymeter (as corneal thickness). Results show that changes of corneal hydration and light absorption appear early after UVB irradiation and increase along with the number of irradiations. In conclusion, irradiation of the rabbit cornea with UVB rays leads to harmful changes of its optical properties.

\section{Key words}

Corneal hydration - Corneal light absorption - Absorption coefficients $\bullet$ UVB rays

\section{Corresponding author}

J. Čejková, Laboratory of Eye Histochemistry and Pharmacology, Institute of Experimental Medicine, Academy of Sciences of the Czech Republic, Vídeňská 1083, 14220, Prague 4, Czech Republic. Fax: 420 241062692. E-mail: cejkova@biomed.cas.cz

\section{Introduction}

With the depletion of the ozone layer, a danger to biological systems arises from the increased penetration of UV rays of longer (UVA) as well as shorter (UVB) wavelength, known to induce reactive oxygen species generation (superoxide and hydroxyl radicals, hydrogen peroxide, singlet oxygen) (Messeley and Mackie 1997, Young 1997, Wenk et al. 2001). These toxic oxygen products are dangerous to biological systems, causing cellular damage by reacting with lipids, proteins and DNA (Kehrer 1993, Wei et al. 2009).

The eye and particularly the cornea are directly exposed to UV rays. The cornea absorbs and detoxifies the majority of UVB rays (approximately $80 \%$ ), and thus it acts as a UVB filter. These processes are ensured by corneal tissue components and fluids containing important low molecular weight antioxidants (Ringvold 1997, 1998, Brubaker et al. 2000, Ringvold et al. 2000, Bilgihan et al. 2001, 2003) as well as high molecular

PHYSIOLOGICAL RESEARCH • ISSN 0862-8408 (print) • ISSN 1802-9973 (online)

(c) 2010 Institute of Physiology v.v.i., Academy of Sciences of the Czech Republic, Prague, Czech Republic

Fax +420 241062 164, e-mail: physres@biomed.cas.cz, www.biomed.cas.cz/physiolres 
weight antioxidants (Atalla et al. 1988, Behndig et al. 1988, Abedinia et al. 1990, Downes et al. 1992, Uma et al. 1996, Pappa et al. 2001, Piatigorski 2001). Of the anterior eye segment tissue components, the corneal layers (particularly the epithelium) play the key role in the protection of the inner eye against the effect of UVB rays (Mitchell and Cenedella 1995, Kolozsvari et al. 2002, Podskochy 2004).

Irradiation of the cornea with UVB rays leads to profound morphological disturbances of the cornea (Koliopoulos et al. 1979, Haaskjold et al. 1993, Podskochy et al. 2000, Čejková et al. 2001, 2004, Rogers et al. 2004), release of pro-inflammatory cytokines (Kennedy et al. 1997) as well as decrease in corneal antioxidants: superoxide dismutase and glutathione peroxidase (Čejková et al. 2000, Lodovici et al. 2003), aldehyde dehydrogenase (Downes et al. 1992, Manzer et al. 2003), and ascorbic acid (Tessem et al. 2005). In contrast, reactive oxygen and nitrogen species are generated in increased amounts (Čejková et al. 2001, 2005).

Tessem et al. (2005) found that five days of repeated irradiation of the rabbit cornea with UVB rays (daily dose $1.6 \mathrm{~J} / \mathrm{cm}^{2}$ ) evoked significant changes in metabolites in the cornea. Using similar mode of irradiation and the daily dose $1.01 \mathrm{~J} / \mathrm{cm}^{2}$, Čejka et al. (2007) described that the irradiated cornea with increased hydration absorbed much more light (particularly in the UVB region) than the normal cornea. The aim of this investigation was to examine at which time interval of irradiation with UVB rays the changes of corneal hydration and light absorption start to be increased. Therefore, the rabbit corneas were irradiated with UVB rays once a day (daily dose $1.01 \mathrm{~J} / \mathrm{cm}^{2}$ ) for one, two, three or four days, and corneal light absorption (together with the corneal thickness) was investigated.

\section{Methods}

\section{UVB irradiation of rabbit corneas}

Adult New Zealand white rabbits $(2.5-3.0 \mathrm{~kg})$ were used in our experiments. The investigation was conducted according to the ARVO Statement for the Use of Animals in Ophthalmic and Vision Research. Rabbits were anesthetized by an i.m. injection of Rometar (Xylazinum hydrochloricum, Spofa, Prague, CR, $2 \%$, $0.2 \mathrm{ml} / \mathrm{kg} \quad$ b.w.) and Narkamon (Ketaminum hydrochloricum, Spofa, $5 \%, 1 \mathrm{ml} / \mathrm{kg}$ b.w.). The rabbits were divided into four groups (each group consisted of six rabbits). The open eyes of the rabbits (both eyes of each rabbit under general anesthesia) were irradiated with a UVB lamp (Bioblock Scientific, Illkirch Cedex, France; $312 \mathrm{~nm}$ wavelength, $6 \mathrm{~W}$ ) from a distance of $0.03 \mathrm{~m}$ for $5 \mathrm{~min}$, once a day (the dose per day was $1.01 \mathrm{~J} / \mathrm{cm}^{2}$ ). Only the corneas were irradiated; the rest of the eye surface was protected from UV rays. The first group of rabbits was irradiated once, the second group two times, the third group three times and the fourth group of animals four times. (After every irradiation of animals and awaking from anesthesia, analgesia was performed: Ketonal, ketoprofenum, Ljubljana, Slovenia, $1.0 \mathrm{mg} / \mathrm{kg}$, i.m. injection). A UV lamp stand - with an exactly determined distance between the lamp and the eyes - was employed for irradiation. The plane of the lamp was parallel to the tangential plane of the eye (at a right angle to the optical axis of the eye). The intensity of total dose of irradiation was measured with Cole-Parmer radiometer equipped with UVB probe (instruments manufactured by Cole-Palmer Inc., Vernon Hills, Illinois, USA). The total dose of irradiation was also checked using these devices. Although the used source of UVB emits only UVB rays with a peak at $312 \mathrm{~nm}$ (according to the irradiation spectrum given by the manufacturer), a UVC sensor (Cole-Parmer Inc.) was employed to detect any potential emission of UVC rays. After finishing the last irradiation (day 1, 2, 3 or 4), the animals were left without further irradiation for $24 \mathrm{~h}$, then they were anesthetized by an i.m. injection of Rometar (Xylazinum hydrochloricum, $2 \%$, Spofa, $0.2 \mathrm{ml} / \mathrm{kg}$ b.w.) and Narkamon (Ketaminum hydrochloricum, $5 \%$, Spofa, $1 \mathrm{ml} / \mathrm{kg}$ b.w.) and the central thickness of the corneas in each experimental group was measured using an ultrasonic pachymeter SP-100. Subsequently, the animals were sacrificed under thiopental anesthesia (Thiopental, Spofa). Immediately after the death of the animals, the corneas were used for spectrophotometrical analyses. Normal non-irradiated corneas also analyzed spectrophotometrically served as controls.

The central corneal thickness of anesthetized rabbits in each experimental group was measured (using an Ultrasonic Pachymeter SP-100, Tomey Corporation, Nagoya, Japan) before the irradiation procedures and, for every irradiation interval, one day after the end of irradiation before sacrificing the animals.

\section{Spectrophotometry of the whole corneas}

Immediately after the sacrificing the animals the corneas were spectrophotometrically examined. The 


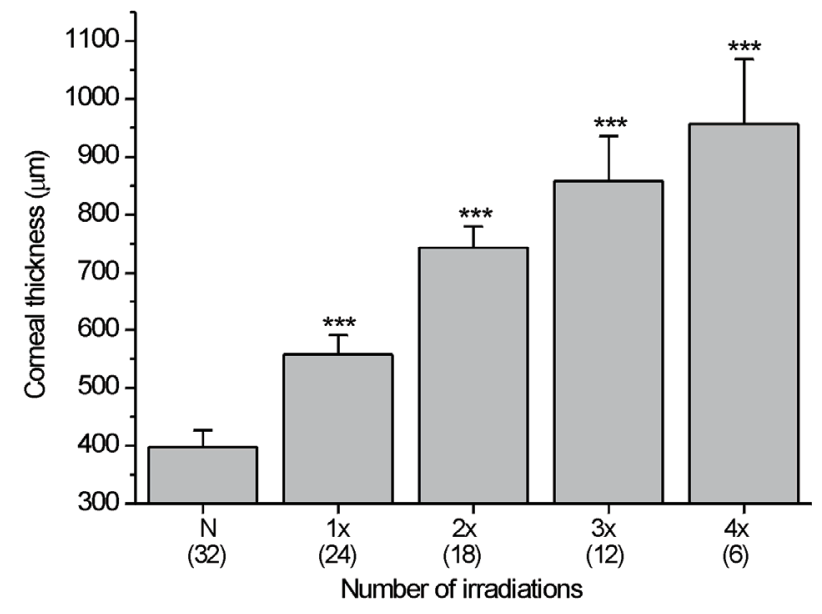

Fig. 1. Thickness of normal corneas and corneas irradiated with UVB rays (daily dose $1.01 \mathrm{~J} / \mathrm{cm}^{2}$ ) once daily for one, two, three or four days. The corneal thickness was measured by an ultrasonic pachymeter at the beginning of each experiment, before each irradiation, and before sacrificing the animals (the total number of measurements is indicated under each column). $* * *$ significantly different $(p<0.001)$ when compared to normal corneas.

corneas were excised from the sclera. From the center of each cornea a circle of $6 \mathrm{~mm}$ diameter was cut out using a special circular knife. Each of these circles was placed into a $6 \mathrm{~mm}$ diameter hole in a stainless steel sheet insert, covered on both sides with quartz glass, and the whole assembly was placed between two halves of an insert (made of acryl glass) designed to fit inside a standard quartz cuvette. The insert also contained a $6.0 \mathrm{~mm}$ hole that coincided with the measuring light beam of the spectrophotometer, and the instrumental light entered the measured piece of cornea from the epithelial side, i.e. from the same direction as light entered the cornea in situ.

The stainless steel sheets were manufactured in advance in the growing row of thicknesses $(0.4,0.5,0.6$, $0.7,0.8,0.9,1.0,1.1,1.2,1.3 \mathrm{~mm})$. For the spectrophotometrical measurement, the insert with the same thickness as the thickness of the normal or irradiated cornea or the nearest higher sheet insert thickness was used.

Before the spectrophotometrical measurements, the corneas (with the whole assembly described above) were submersed into $340 \mathrm{mOsm} / \mathrm{kg}$ PBS in the measuring cuvette. Reference spectrophotometrical measurements (with metal sheets for normal and irradiated corneas) were conducted with the same assembly bathed in the same solution (only without the samples). The absorbance readings were made over a range of wavelengths 300-650 nm using a HELIOS b 84021 v4.55
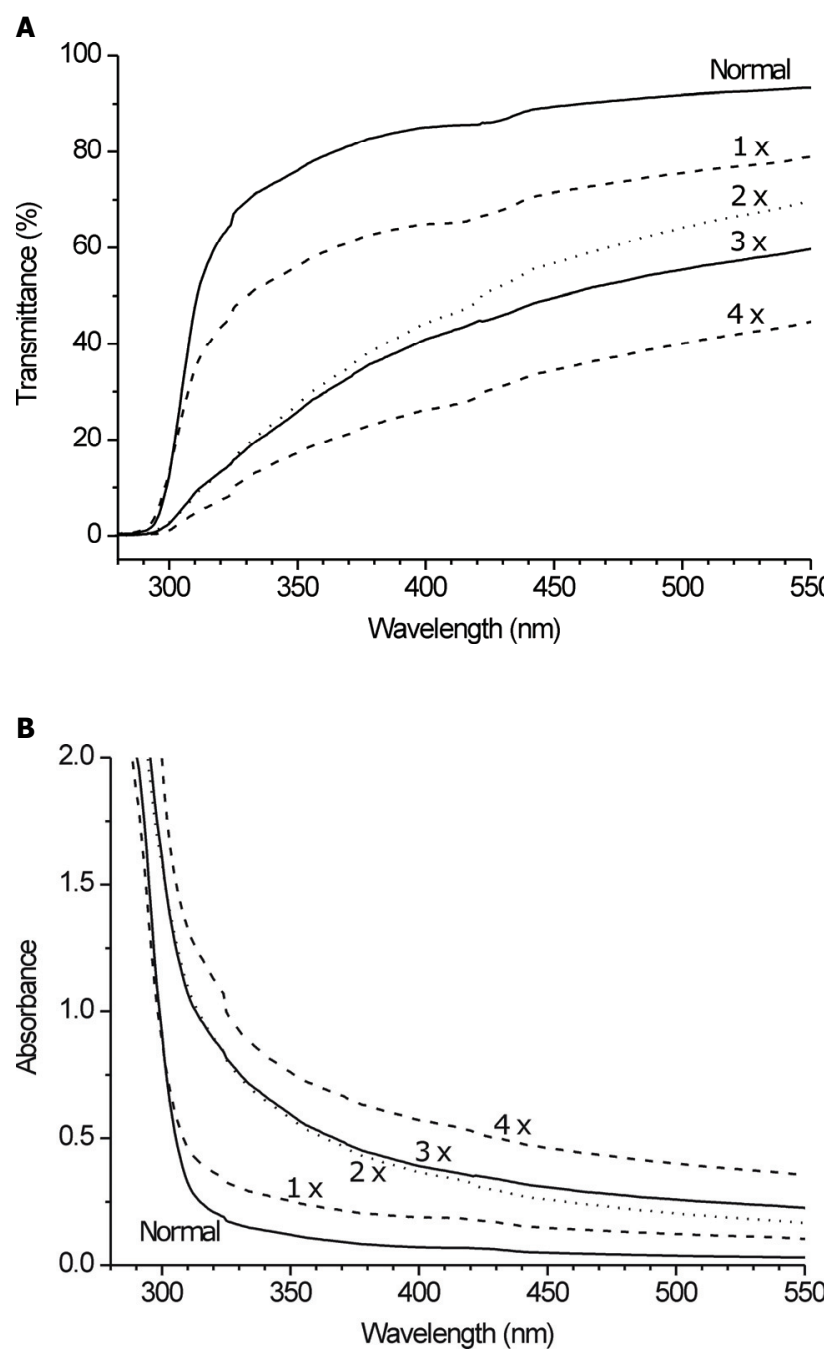

Fig. 2. Results of the spectrophotometry of the corneal centers, expressed either as the spectrum of transmittance $T=T(\lambda)(\mathbf{A})$, or absorbance $A=A(\lambda)(\mathbf{B})$ of normal corneas and corneas irradiated with UVB rays $\left(1.01 \mathrm{~J} / \mathrm{cm}^{2}\right)$ once daily for one $(1 \mathrm{x})$, two $(2 x)$, three $(3 x)$ or four $(4 x)$ days. The spectra are averaged from 16 traces for normal corneas and 6 traces for each group of irradiated ones. Significant differences of $T$ and $A$, respectively, in selected wavelengths (312 nm, $320 \mathrm{~nm}, 550 \mathrm{~nm}$ ) between normal corneas and corneas irradiated with UVB rays (1x, 2x, 3x, $4 \mathrm{x}$ ) by one-way ANOVA with Dunnett's post-hoc test were found with the exception of $A$ in $312 \mathrm{~nm}$. (Note that for wavelengths shorter than about $300 \mathrm{~nm}$, the spectra show instrumental stray light error rather than the corneal optical properties).

scanning spectrophotometer (Spectronic Unicam, Cambridge, UK) with a wavelength resolution (step size) of $1 \mathrm{~nm}$. The obtained data were expressed either as the spectrum of transmittance $\mathrm{T}=\mathrm{T}(\lambda)$ or absorbance $\mathrm{A}=\mathrm{A}$ $(\lambda)$.

$$
\mathrm{A}=-\log \mathrm{T}
$$

For the absorbance the following formula is valid: $A=\alpha . d$, where $\alpha\left[\mathrm{mm}^{-1}\right]$ is the coefficient of absorption, and $d[\mathrm{~mm}]$ is the thickness of the light absorbing sample layer. 


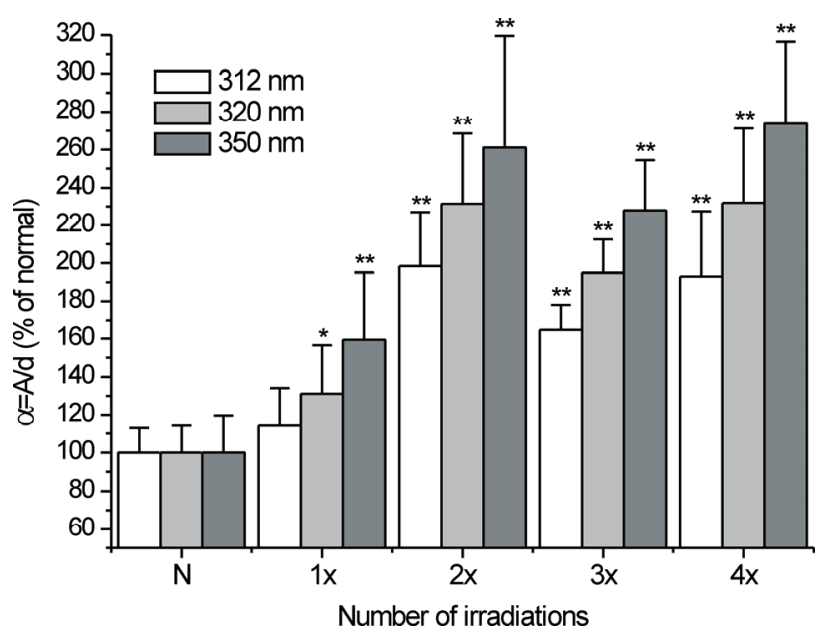

Fig. 3. Corneal optical properties of normal and UVB irradiated corneas shown as the extinction coefficient $\alpha=A / d$. Corneal thickness was taken one day after the end of individual irradiations, before sacrificing the animals for spectrophotometrical examinations. The data were converted to $\%$ of the mean of normal values for each selected wavelength. $n=16$ for normal corneas, and $n=6$ for each group of irradiated ones. Statistically significant differences between the irradiated values and the corresponding normal values are marked with * $(p<0.05)$ or $* *(p<0.01)$.

\section{Statistics}

The data are generally presented as mean \pm S.D. The Kruskal-Wallis test (non-parametric ANOVA) with the Dunn's test was used for statistical evaluation of corneal thickness measurements, while for the absorption coefficient data, ANOVA followed by the Dunnett's test were employed. Both tests were calculated using InStat ver. 3.06 (GraphPad Software, Inc., San Diego, CA).

\section{Results}

The corneas irradiated once did not show any macroscopical changes. From day two to day four of repeated irradiation, the corneas became opalescent (they gradually turned grayish). When the cornea was irradiated four times, corneal vascularization appeared at the limbus (Fig. 4). After one UVB dose, the corneal thickness increased (increased hydration), and continued to increase with every further irradiation (Fig. 1). The increase in corneal hydration was at the beginning linear but later (from day three to day four of irradiation) the increase of corneal hydration became slower. Simultaneously, the transparency of the corneas measured as tissue transmittance also decreased with every irradiation (Fig. 2A). When the spectrophotometrical data for selected wavelengths were converted to the absorption coefficients $(\alpha=\mathrm{A} / \mathrm{d})$, it was evident that the observed changes were not uniform throughout the measured

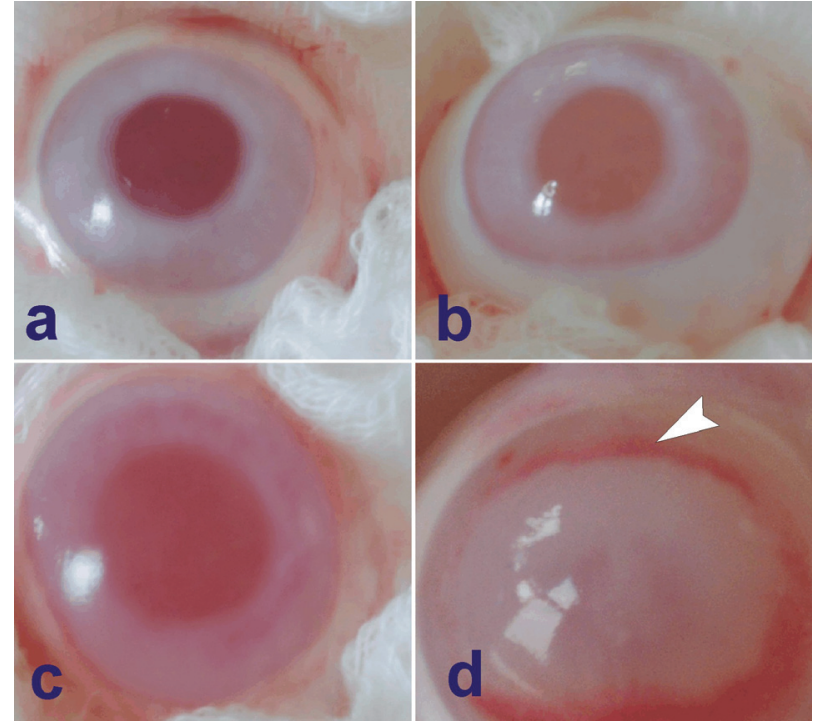

Fig. 4. Macroscopic picture of the normal rabbit cornea and rabbit corneas irradiated with UVB rays. Photographic images were done one day after the end of individual irradiations, immediately after sacrificing the animals. a - normal cornea; b - cornea irradiated once. No changes of corneal transparency can be seen; c - cornea irradiated two times. The corneal transparency is slightly changed (cornea becomes opalescent); d- cornea irradiated four times. The changes of corneal transparency are highly pronounced. Corneal neovascularization appears at the limbus (arrow).

spectral range and that also they depended on the number of irradiations (Fig. 3). Changes in absorption coefficient $\alpha$ against normals (in selected wavelengths) (Fig. 3 ) were significant with the exception of the wavelength $312 \mathrm{~nm}$ after one irradiation. In this case the increase of absorbance A (decrease of transmittance, respectively) (Fig. 2A,B) was caused mainly by the increase in corneal hydration (significant against normal, Fig. 1). In addition, there was a qualitative difference in corneal absorption between single and repeated irradiations, manifesting as a flattening of the transmittance traces with the maximum changes centered around $320 \mathrm{~nm}$ (Figs 2A and 3).

\section{Discussion}

Our results show that the light absorption in the rabbit cornea irradiated with UVB rays increases soon after UVB irradiation, in parallel with an increase in corneal hydration (measured as central corneal thickness). Later (from day two to day four), with repeated irradiation, some other qualitative changes in the composition of the corneal tissue also appear that contribute to further changes in corneal transparency.

The broad increase in corneal light absorption seen even after one UVB irradiation can be a direct 
consequence of increased corneal hydration. Corneal transparency is highly dependent on normal hydration of the cornea (Meek et al. 2003b). Light scattering appears along with corneal swelling. This scattering has been ascribed to the disruption caused by the arrangement of collagen fibres. Changes in the refractive index of the extracellular matrix make only a small contribution to the increase in light scattering when the cornea swells (Meek et al. 2003b). In the hydrated corneal stroma, fluid is not uniformly distributed. This is more pronounced in the posterior lamellae due to known differences in glycosaminoglycans between the anterior and posterior stroma (Meek et al. 2003a).

In our previous studies (Čejková et al. 2001, 2005, Čejka et al. 2007) as well as in papers of other authors (Podskochy 2004, Rogers et al. 2004) the damage of the corneal epithelium and a considerable reduction of epithelial thickness after UVB irradiation were reported. Podskochy et al. (2000) described that apoptosis appeared to be a mechanism of corneal cell death after UVB rays. According to Kennedy et al. (1997) acute UV irradiation exposure results in the induction of corneaderived proinflammatory cytokines. Moreover, the irradiation of the cornea with UVB rays leads to the decrease of antioxidants (Downes et al. 1993, Čejková et al. 2000, Lodovici et al. 2003, Manzer et al. 2003, Tessem et al. 2005), whereas the generation of reactive oxygen and nitrogen species is significantly increased (Čejková et al. 2001, 2005).

Tessem et al. (2005) found that the repeated irradiation of the cornea with UVB rays for five days (daily dose $1.6 \mathrm{~J} / \mathrm{cm}^{2}$ ) caused significant disturbances of corneal metabolites. Čejka et al. (2007) found that repeated irradiation with UVB rays for five days (daily dose $1.01 \mathrm{~J} / \mathrm{cm}^{2}$ ) evoked greatly increased corneal light absorption throughout the whole measurable spectral range (particularly in the UVB region). In this paper it was reported that the cornea absorbed more light already after one daily dose of UVB rays $\left(1.01 \mathrm{~J} / \mathrm{cm}^{2}\right)$. Examination of the absorption coefficient $\alpha$ at various wavelengths suggests that the increase in corneal light absorption is initially mainly due to an increase in corneal hydration and later - with further irradiation - also due to changes in corneal composition that further increase corneal light absorption (decrease corneal transparency) at certain wavelengths. These latter changes will be the subject of our next study.

Zigman (1995) described a dose of $0.105 \mathrm{~J} / \mathrm{cm}^{2}$ of UVB rays during 1 hour exposure of the human cornea to sunlight. When we compare our daily UVB dose of $1.01 \mathrm{~J} / \mathrm{cm}^{2}$ with the dose calculated for solar UVB radiation reaching the human cornea, our dose is equivalent to 10 hours exposure time in sunlight (the approximate summer daily exposure). Our results show that this dose evoked a significant increase in corneal hydration and light absorption.

In conclusion, the repeated irradiation of the cornea with UVB rays leads to the profound changes of its optical properties.

\section{Conflict of Interest}

There is no conflict of interest.

\section{Acknowledgements}

Supported by a grant from the Grant Agency of Charles University of the Czech Republic No. 47/2006/C/2.LF and by a grant from the Academy of Sciences of the Czech Republic AV0Z50390512.

\section{References}

ABEDINIA M, PAIN T, ALGAR EM, HOLMES RS: Bovine corneal aldehyde dehydrogenase: the major soluble protein with a possible dual protective role for the eye. Exp Eye Res 51: 419-426, 1990.

ATALLA LR, SEVANIAN A, RAO NA: Immunohistochemical localization of glutathione peroxidase in ocular tissues. Curr Eye Res 7: 1023-1027, 1988.

BEHNDIG A, SVENSSON B, MARKLUND SL, KARLSSON K: Superoxide dismutase isoenzymes in the human eye. Invest Ophthalmol Vis Sci 39: 471-475, 1988.

BILGIHAN A, BILGIHAN K, TOKLU Y, KONUK O, YIS O, HASANREISOGLU B: Ascorbic acid levels in human tears after photorefractive keratectomy, transepithelial photorefractive keratectomy, and laser in situ keratomileusis. J Cataract Refract Surg 27: 585-588, 2001.

BILGIHAN A, BILGIHAN K, YIS O, CEZER C, AKYOU G, HASANREISOGLU B: Effects of topical vitamin E on corneal superoxide dismutase, glutathione peroxidase activities and polymorphonuclear leukocyte infiltration after photorefractive keratectomy. Acta Ophthalmol Scand 81: 177-180, 2003. 
BRUBAKER RF, BOURNE WM, BACHMAN LA, MCLAREN JW: Ascorbic acid content of human corneal epithelium. Invest Ophthalmol Vis Sci 41: 1681-1683, 2000.

ČEJKA Č, PLÁTENÍK J, GURYCA V, ŠIRC J, MICHÁLEK J, BRŮNOVÁ B, ČEJKOVÁ J: Light absorption properties of the rabbit cornea repeatedly irradiated with UVB rays. Photochem Photobiol 83: 652-657, 2007.

ČEJKOVÁ J, ŠTÍPEK S, CRKOVSKÁ J, ARDAN T: Changes of antioxidant enzymes in the cornea of albino rabbits irradiated with UVB rays. Histochemical and biochemical study. Histol Histopathol 15: 1043-1050, 2000.

ČEJKOVÁ J, ŠTÍPEK S, CRKOVSKÁ J, ARDAN T, MIDELFART A: Reactive oxygen species (ROS)-generating oxidases in the normal rabbit cornea and their involvement in the corneal damage evoked by UVB rays. Histol Histopathol 16: 523-533, 2001.

ČEJKOVÁ J, ŠTÍPEK S, CRKOVSKÁ J, ARDAN T, PLÁTENÍK J, ČEJKA Č, MIDELFART A: UV rays, the prooxidant/antioxidant imbalance in the cornea and oxidative eye damage. Physiol Res 53: 1-10, 2004.

ČEJKOVÁ J, ARDAN T, ČEJKA Č, KOVAČEVA J, ZÍDEK Z: Irradiation of the rabbit cornea with UVB rays stimulates the expression of nitric oxide synthases-generated nitric oxide and the formation of cytotoxic nitrogen-related oxidants. Histol Histopathol 20: 467-473, 2005.

DOWNES JE, VANDEBERG JL, HUBBARD GH, HOLMES RS: Regional distribution of mammalian corneal aldehyde dehydrogenase and alcohol dehydrogenase. Cornea 11: 560-566, 1992.

HAASKJOLD E, OLSEN WM, BJERKNES R, KRAVIK K: Early cell kinetic effects of a single dose of narrowbanded ultraviolet B irradiation on the rat corneal epithelium. Photochem Photobiol 57: 663-666, 1992.

KEHRER JP: Free radicals as mediators of tissue injury and disease. Crit Rew Toxicol 23: 21-48, 1993.

KENNEDY M, KIM KH, HARTEN B, BROWN J, PLANCK S, MESHUL C, EDELHAUSER H, ROSENBAUM JT, ARMSTRONG CA, ANSEL JC: Ultraviolet irradiation induces the production of multiple cytokines by human corneal cells. Invest Ophthalmol Vis Sci 38: 2483-2491, 1997.

KOLIOPOULOS JX, MARGARITIS LH: Reponse of the cornea to far ultraviolet light: an ultrastructural study. Ann Ophthalmol 11: 765-769, 1979.

KOLOZSVÁRI L, NÓGRÁDI A, HOPP B, BOR Z: UV-absorbance of the human cornea in the 240- to 400-nm range. Invest Ophthalmol Vis Sci 43: 2165-2168, 2002.

LODOVICI M, RAIMONDI L, GUGLIELMI F, GEMIGNANI S, DOLARA P: Protection against ultraviolet B-induced oxidative DNA damage in rabbit corneal-derived cells (SIRC) by 4-coumaric acid. Toxicology 184: 141-147, 2003.

MANZER R, PAPPA A, ESTEY T, SLADEK N, CARPENTER F, VASILIOU V: Ultraviolet radiation decreases expression and induces aggregation of corneal ALDH3A1. Chem Biol Interact 143-144: 45-53, 2003.

MEEK KM, DENNIS S, KHAN S: Changes in refractive index of the stroma and its extrafibrillar matrix when the cornea swells. Biophys $J$ 85: 2205-2212, 2003a.

MEEK KM, LEONARD DW, CONNON CJ, DENNIS S, KHAN S: Transparency, swelling and scarring in the corneal stroma. Eye 17: 927-936, 2003b.

MESELEY H, MACKIE RM: Ultraviolet B radiation was increased at ground level in Scotland during a period of ozone depletion. Br J Dermatol 137: 1001-102, 1997.

MITCHELL J, CENEDELLA RJ: Quantification of ultraviolet light-absorbing fractions of the cornea. Cornea 14: 266272, 1995.

PAPPA A, SOPHOS NA, VASILIOU V: Corneal and stomach expression of aldehyde dehydrogenases: from fish to mammals. Chem Biol Interact 130-132: 181-191, 2001.

PIATIGORSKI J: Enigma of the abundant water-soluble cytoplasmic proteins of the cornea: the "refracton" hypothesis. Cornea 20: 853-858, 2001.

PODSKOCHY A: Protective role of corneal epithelium against ultraviolet radiation damage. Acta Ophthalmol Scand 82: 714-717, 2004.

PODSKOCHY A, GAN L, FAGERHOLM P: Apoptosis in UV-exposed rabbit corneas. Cornea 19: 99-103, 2000.

RINGVOLD A: In vitro evidence for UV-protection of the eye by the corneal epithelium mediated by the cytoplasmic protein, RNA, and ascorbate. Acta Ophthalmol Scand 75: 496-498, 1997.

RINGVOLD A: Corneal epithelium and UV-protection of the eye. Acta Ophthalmol Scand 76: 149-153, 1998. 
RINGVOLD A, ANDERSSEN E, KJONNIKSEN I: Distribution of ascorbate in the anterior bovine eye. Invest Ophthalmol Vis Sci 41: 20-23, 2000.

ROGERS CS, CHAN LM, SIMS YS, BYRD KD, HINTON DL, TWINING SS: The effects of sub-solar levels of UV-A and UV-B on rabbit corneal and lens epithelial cells. Exp Eye Res 78: 1007-1014, 2004.

TESSEM MB, MIDELFART A, ČEJKOVÁ J, BATHEN TF: Effect of UV-A and UV-B irradiation on the metabolic profile of rabbit cornea and lens analysed by HR-MAS ${ }^{1} \mathrm{H}$ NMR spectroscopy. Ophthalmic Res 38: 105-114, 2005.

UMA L, HARIHARAN J, SHARMA S, BALASUBRAMANIAN D: Effect of UVB radiation on corneal aldehyde dehydrogenase. Curr Eye Res 15: 685-690, 1996.

WEI YH, WU SB, MA YS, LEE HC: Respiratory function decline and DNA mutation in mitochondria, oxidative stress and altered gene expression during aging. Chang Gung Med J 32: 113-132, 2009.

WENK J, BRENNEISEN P, MEEWES C, WLASCHEK M, PETERS T, BLAUDSCHUN R, MA W, KUHR L, SCHNEIDER L, SCHARFFETTER-KOCHANEK K: UV-induced oxidative stress and photoaging. Curr Probl Dermatol 29: 83-94, 2001.

YOUNG AR: The biological effect of ozone depletion. Br J Clin Pract 89: 10-15, 1997.

ZIGMAN S: Environmental near-UV radiation and cataracts. Optom Vis Sci 72: 899-901, 1995. 